\title{
Analyzing physical spaces as a means of understanding rhetoric
}

\author{
Roger Chao*
}

$2 / 3 / 2020^{\dagger}$

\begin{abstract}
The following collaborative project is designed to encourage students to investigate how rhetoric functions in everyday locations. Specifically, this assignment prompts students to document, analyze, and present the physical design and makeup of "privately owned public spaces" (POPS), a unique categorization of community spaces that is promoted as simultaneously private and public. The benefits of completing this assignment are multifaceted: students are given the opportunity to experience learning beyond the confines of the classroom, and students are able to practice rhetorical analysis on physical locations, thereby learning how rhetoric functions beyond written or verbal discourse and attuning them to the social contexts of public spaces.
\end{abstract}

When instructors introduce the term "rhetoric" to their students in a traditional composition course, they often associate it with either the spoken word or the written text. A charismatic speaker is called a rhetorician; sometimes students are asked to unpack the "fuzzy" rhetoric of deceptive propaganda. By analyzing spoken and written text, students learn how language can be used to move audiences to think or behave in certain ways. However, rhetoricians like Nedra Reynolds also acknowledge the rhetoric of physical spaces; in Geographies of Writing, Reynolds (2007) argues that "geographical locations influence our habits, speech patterns, style, and values - all of which make it a rhetorical concept or important to rhetoric" (p. 11). In helping mold our lived experiences, the physical environments that we navigate and inhabit function as texts also worthy of in-depth rhetorical analysis.

An examination of space and place through a rhetorical lens would therefore help expand students' understanding of how behavior can be influenced by forces beyond written and spoken text. To facilitate such an examination, I designed a 200-level rhetorical theory course at the University of Washington in Seattle, Washington. Titled "The Rhetoric of

\footnotetext{
*Oakland University, rogerchao@oakland.edu. Copyright 2020 Roger Chao. This work is licensed under a Creative Commons Attribution-NonCommercial 4.0 International License (http://creativecommons.org/licenses/by-nc/4.0/).

${ }^{\dagger}$ Submitted, 10/27/2018; Accepted, 10/29/2019.
} 
Space and Place," the 10-week course explores everyday built environments and covers topics like urban design, gentrification, and human migration. In this class, students work towards achieving three overall objectives. First, students develop their close reading skills by unpacking complex concepts found in the readings, a process facilitated by discussions and assignments. Second, the course promotes students' understanding of primary research by prompting them to draw on their fieldwork and observations as support for their arguments. The third and final objective emphasizes reflection as a tool for composing; specifically, students synthesize their personal experiences of space/place interactions with theories in assigned readings, looking for moments of parallel, disparity, and complication.

While designing this course, my pedagogy was influenced primarily by material rhetoric scholarship. Conceptualizing physical spaces as a meaning-making force has been a longstanding thought within rhetorical theory; theorists like Michael Calvin McGee (1982) viewed rhetoric as a socially oriented force that can be enacted by nonhuman entities and have the ability to create something tangible. For nonhuman subjects like physical spaces, their influence can be understood through the behaviors and actions they afford or prohibit to those who interact with them. More recently, scholar Candice Rai (2016) furthers the argument of locations having a rhetorical force capable of producing social effects. As she articulates, "rhetoric is not only made visible and transported by material carriers, but also emerges from and is brought to life by the particular environs already present in the world. Rhetoric is emplaced, embodied, and embedded in the... very forms of being of everyday life" (p. 6). My pedagogy was also influenced by community-based writing scholarship, which suggests that a comprehensive understanding of rhetoric cannot be achieved when the bridge between the university and the surrounding publics is merely imagined (Deans, 2000; Guerra, 2015; Wells, 1996); rather, students must physically leave the classroom and work within actual community spaces. Synthesizing material rhetoric and community-based writing scholarship, I designed an assignment that culminated in a presentation based on the rhetoric of everyday locations by directly placing them into Seattle's varied cityscape. My hope was that through this assignment, students would have the opportunity to apply a materialist rhetorical perspective to their understanding of how rhetoric functions "in the wild": in public life and beyond traditionally examined texts like billboards or advertisements.

During the first week of class, students were organized into groups and assigned a "privately owned public space" (POPS) to investigate. As part of The Monson Plan, a program in 1963 that attempted to improve downtown Seattle, the city permitted corporate buildings to be constructed as long as they also provided a public benefit"some kind of park or outdoor space that's open to visitors, whether it be on the grounds surrounding the building or contained secretly within it" (van Huygen, 2018). The POPS that students investigated ranged in size and type, including rooftop gardens, plazas, and nature reserves. My rationale for selecting POPS as the sites of inquiry was based on two factors. First, while the university campus itself would have been an acceptable research location, it was imperative that students explored locations beyond the comfort 
of the college environment. As scholars like Johnathon Mauk (2003) suggest, we must complicate and expand our definitions of academic spaces beyond the boundaries of the university campus. Instead, students and instructors alike ought to reimagine the locations outside of the classroom and campus as learning environments as well.

Second, the identity of each POPS as a blended public and private space offered a unique site for rhetorical analysis. Curbed, a popular real estate blog, notes that "although they're located on private property, each POPS offers the same rights to its occupants as a public park would, such as free speech and freedom of assembly" (van Huygen, 2018). The POPS' ambiguous designation parallels other concerning conversations around the increasing privatization of land and the resulting loss of public spaces in cities. Kevin Michael DeLuca and Jennifer Peeples (2002) note that "corporate interests are inextricably entwined in 'public' activities" (p. 126). Stephan Schmidt (2008) concurs, suggesting that urban spaces have increasingly become more privatized, with businesses owning and maintaining traditional public spaces such as parks and atria. As a result, "the typology of local open space preservation and the manner in which local planners are involved has become increasing complex and less easy to characterize" (p. 18). In the case of POPS, their liminality is often expressed through features such as location, accessibility, and permitted activities. For example, a free and publicly accessible viewpoint called the Sky Lobby goes largely unknown due to its location on the $40^{\text {th }}$ floor of Seattle's Columbia Center, a privately-owned skyscraper. Therefore, through this assignment, I wanted students to employ their rhetorical analysis skills by examining the tension that is created when a physical location is not entirely public nor entirely private but rests somewhere in between.

\section{Assignment Description}

This assignment provides students with the opportunity to demonstrate and practice close reading, primary research, and reflection, each of the three previously-mentioned course objectives. Prior to visiting the assigned POPS, the class practiced close reading by dissecting texts that laid out key concepts related to spatial rhetoric. Specifically, we examined chapters from Tim Cresswell's (2004) Place: An Introduction to define and distinguish among "place," "space," and "landscape"; Yi-Fu Tuan's (1977) Space and Place to cover how human senses affect the perception of environments; and Ray Oldenburg's (1999) The Great Good Place to recognize how communities depend on shared locations where the public can come together and exchange ideas. Once students identified some of the governing theories on space and acquired the vocabulary to articulate their observations, each group traveled to their assigned POPS and conducted primary research by documenting characteristics such as accessibility, layout, and signage using photography, video, and/or audio.

To help students analyze their observations, I reconceptualized a heuristic published in Karla Saari Kitalong and Marcia Muth's textbook Getting the Picture: A Brief Guide to Understanding and Creating Visual Texts (2004) that was originally intended for analyzing 
visual rhetoric. The modified heuristic provided students with three levels of guided questions that, when followed sequentially, facilitated further unpacking of each POPS' rhetoric. At the first level, students began by identifying the rhetorical situation in which the space is embedded, accounting for its history, participants, and the exigence behind its formation. At the second level, students documented the physical characteristics of the space. Finally, the third level prompted students to uncover the connotation behind those characteristics and the effects they have on those who interact with the space.

After fieldwork and analysis, the groups were required to create an in-class presentation that introduced a claim (or interrelated sub-claims) about the rhetorical nature of their POPS. Students were required to use their observations as supporting evidence, thus granting them an opportunity to demonstrate the second course objective. Each group then selected a different day to present their work to the rest of their classmates. Students also synthesized their primary research with the theories they encountered in the course readings, thereby demonstrating the third course objective to utilize reflection during the composing process. By asking students to integrate scholarship into their final presentation, my intention was to move them away from simply describing the physical makeup of their POPS and instead analyze how their primary research paralleled or challenged the established arguments on spatial rhetoric. Before their presentation, groups were asked to submit a copy of the presentation as well as their talking points for grading purposes. Presentations lasted 20-30 minutes and concluded with a question and answer session between the presenters and audience. In terms of assessment, criteria to evaluate presentations included strength of claim, utilization of primary research, and application of course readings as a lens for analysis. Students were also assessed individually on their tone and delivery.

Another detail I considered when designing this assignment was my students' safety and well-being as they traveled around Seattle. Jordynn Jack (2009) encourages instructors to carefully consider the ideological and ethical implications of community-based work. Along with informing students on the academic specifics of each assignment, Jack suggests that instructors compose guidelines that would help students work in public spaces in a legal and safe manner. During one-on-one conversations with my students, some expressed an initial hesitation about traveling to and parking near the POPS located in Downtown and South Seattle, where economic disparities are much more visible compared to the neighborhoods surrounding the campus. Populations affected by homelessness, while noticeable throughout Seattle, intensify in density as one nears the heart of the city. I was also aware that the private/public duality of the POPS might raise entry and privacy issues. To address these concerns, I included a guideline to prepare students for challenges that may arise during their fieldwork. In the language of my prompt, students were reminded that despite each POPS being open to the public, they were still privately-owned locations and groups may face questioning from security or staff. While some students initially felt discomfort entering unfamiliar parts of the city, it was also important that students were prepared for the dynamic nature of the research process; scholars like Julie Drew (2001) push for the abolition of thinking about learning in a 
neat, structured way, instead suggesting the classroom should be "within the pedagogical, rather than locate the pedagogical within the classroom" (p. 61). By acknowledging that moments of discomfort could potentially occur, I wanted to drive home the idea that opportunities for learning can exist in places outside of the college environment and that learning itself may be unpredictable but ultimately beneficial for one's social consciousness.

\section{Student Takeaways}

Overall, students enjoyed the chance to explore the surrounding communities and examine everyday locations in a critical fashion. One student mentioned a more nuanced understanding of rhetoric, noting in their final course evaluation that "it was interesting to think about space and place as a text, which is something I have not done before." In their presentations, students successfully analyzed the rhetoric of their POPS by not only identifying unique design features but also considering the implications of the features on those who interact with the space. For example, upon visiting a park known as Kubota Gardens, one group documented the rough, uneven terrain of the park and argued that the POPS was inaccessible to visitors with mobility impairments (see Figure 1). Another group recorded the sound of the man-made waterfall in Waterfall Gardens, a POPS located in the heart of downtown Seattle, and suggested that the space created a calming, natural state for visitors by drowning out the noise of the surrounding city.

\section{Excludes the disabled}
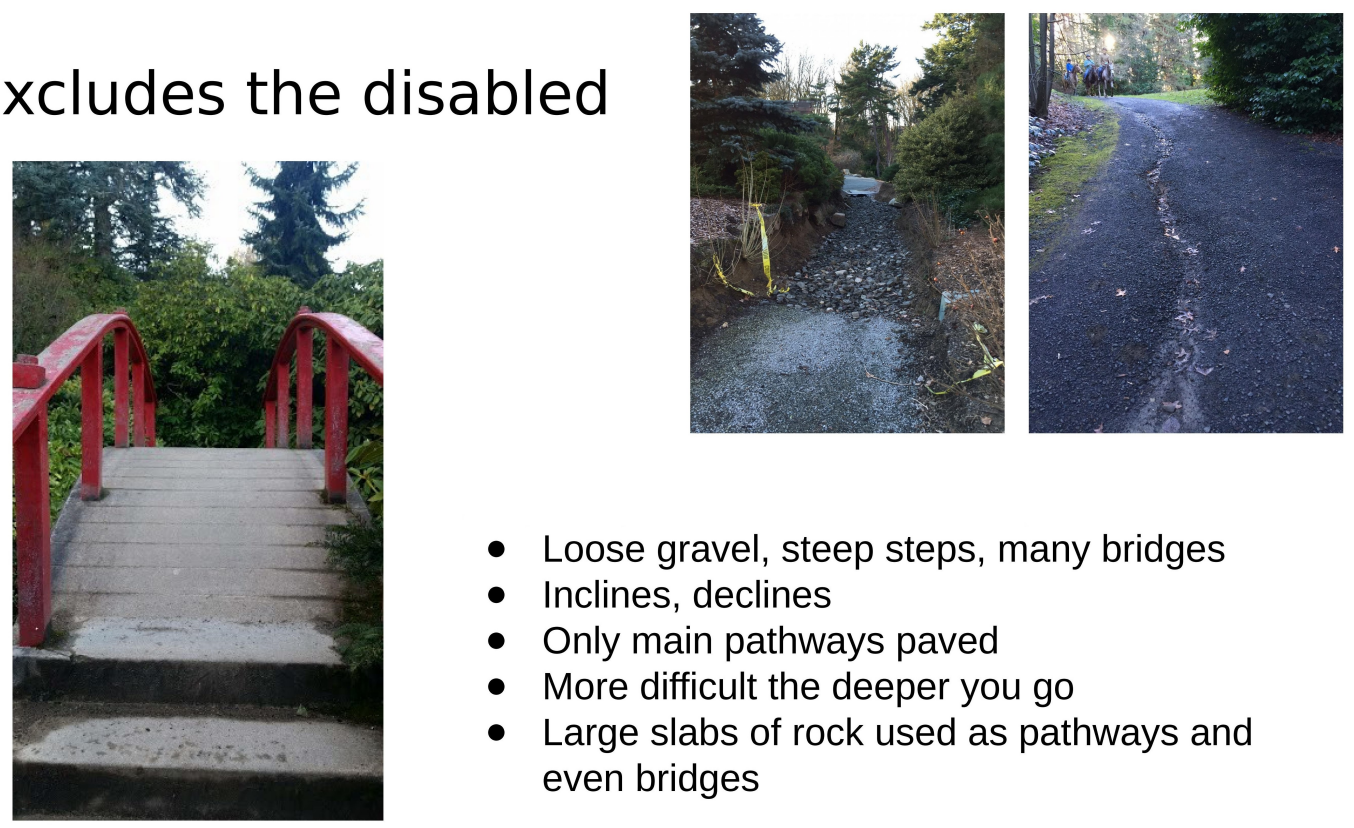

- Loose gravel, steep steps, many bridges

- Inclines, declines

- Only main pathways paved

- More difficult the deeper you go

- Large slabs of rock used as pathways and even bridges

Figure 1: Group presentations for this assignment not only documented their POPS' design features but also analyzed the implications of such features on the visiting public.

In addition, some groups used their presentation to highlight complications that arose 
due to the POPS' dual public/private identity. In the talking points of a group that investigated a plaza located downtown, one student pointed out the unclear nature of ownership over a POPS:

The building itself has been transferred in ownership rights several times. First it was owned by Seafirst Bank, and then Bank of America, now the ownership rights have been transferred back to the original developer of the building, Hines.... With this context in mind, the question of who maintains this POPS location comes to thought. Is it the owner of the land, the major tenant of the building, or the major owner of the building?

Other groups were able to identify how the liminality of these POPS revealed itself in the very material that constructed the space. For example, when documenting a space known as the Garden of Remembrance, one group photographed a contradicting sequence of signs that promoted the area as a public space yet also prohibited loitering and food and drink consumption - rules that are often found in private spaces (see Figure 2). This led the students to ask in their presentation, "What is truly meant by the term 'public space'? If there is no loitering, food, or drinks allowed, then what is allowed?" By leaving the confines of the classroom and campus, these students were able to understand, firsthand, how physical spaces like POPS contain a rhetorical force that affects all those who visit them, sometimes in paradoxical ways.

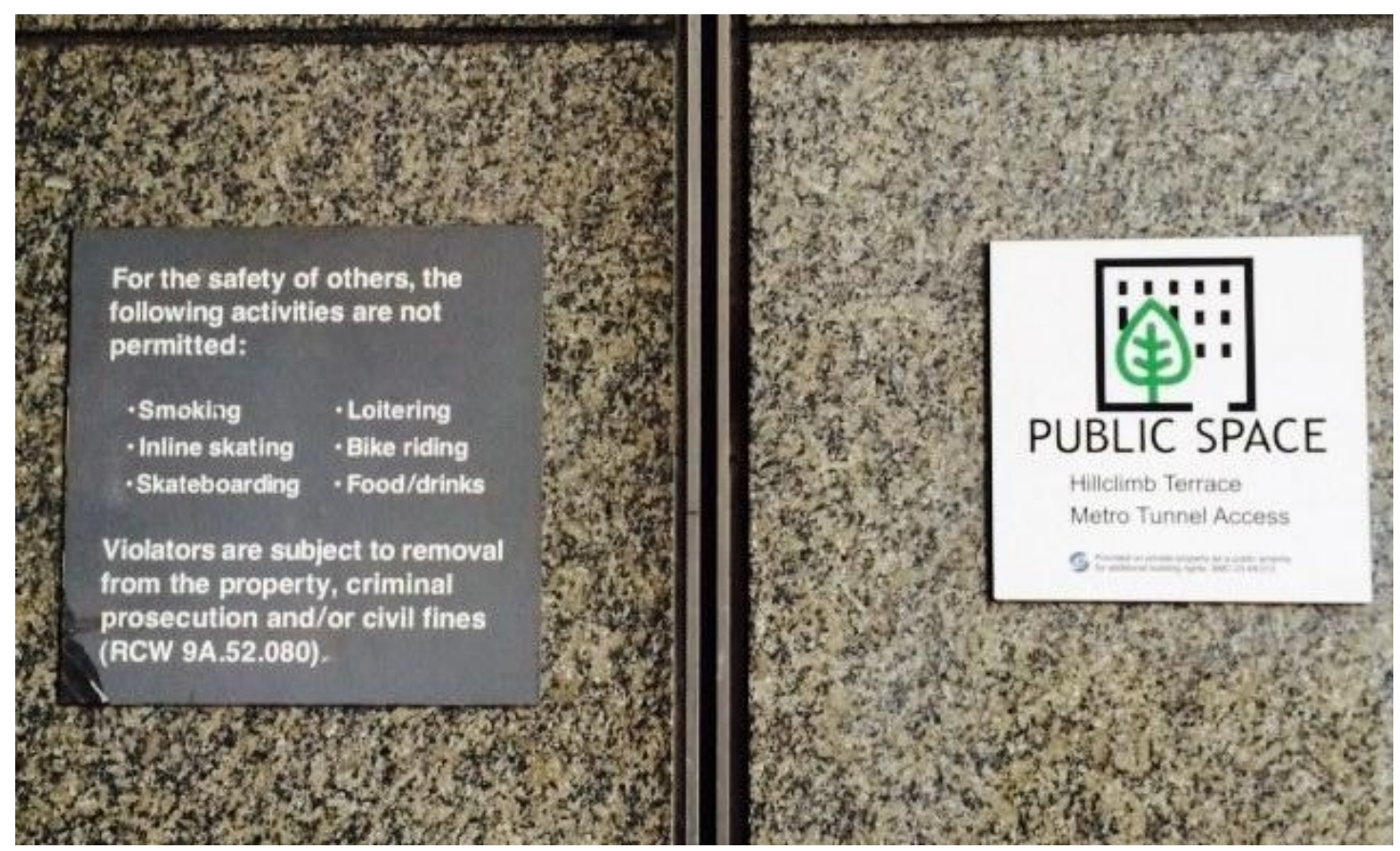

Figure 2: The complicated nature of a dual public/private space was sometimes revealed in the tangible material that made up the POPS. 


\section{Factors to Consider}

Two factors that significantly impacted this assignment's design were class size and the length of the academic term. In total, 37 students were enrolled in the course, which ran for 10 weeks. The combination of a relatively short timeline and a moderately large class size made it challenging to create assignments that could be assessed with meaningful feedback in a reasonable amount of time. While I would have preferred each student turn in an additional supplemental essay in which they unpacked their claim and analyses further, the labor required to evaluate 37 papers in addition to the presentations would have been extremely time consuming. Given that this course also included two other individual-based, writing-intensive assignments, a traditional research paper and a multimodal essay, I ultimately felt comfortable keeping this one to an in-class presentation format.

For faculty who are considering adapting this assignment for their own context, it should be mentioned that the rhetorical analysis of physical spaces can be achieved in a variety of different settings and is not limited to only urban contexts. Even if there are a limited number of public spaces in your locality, this assignment can be implemented successfully using locations and buildings found on the campus itself. For example, a library, often featuring very distinct areas of work, study, and leisure, makes for an ideal site of exploration. Alternatively, instructors can identify key sociopolitical themes, such as gentrification or public accessibility, and prompt students to identify how these themes physically manifest in their local communities.

\section{Conclusion}

In short, this group assignment encourages students to explore how rhetoric functions in everyday physical spaces. By physically engaging their local communities, students get the opportunity to participate directly in the primary research process. Then, by reflecting on their experiences in the field as well as the theories and concepts discussed in the classroom, students work to unpack the nuanced and sometimes perplexing nature of the locations around them. Finally, by bringing their findings and analyses back into the classroom and presenting it to their fellow classmates, students construct a shared understanding of how rhetoric works in the environment that all of them move through, around, and between.

\section{Assignment: POPS Investigation and Presentation}

(To view a PDF facsimile of the original formatting of this assignment, return to this article's homepage and locate the link to the "Assignment" PDF.)

As we move through this class, our understanding of space and place will become more and more complicated and nuanced. We will encounter various definitions and perceptions 
of what spaces "do," with some ideas that parallel one another and some that challenge one another.

You and your group mates will explore one of the POPS locations listed in our syllabus. The goal of this assignment is fairly straightforward: Visit the location and document some of its characteristics. Based on the evidence that you gather, work together to make a claim (or perhaps claims) about the rhetoric of the POPS. In other words, how does the space influence or affect the thoughts, views, or actions of those who interact with it? Then, on the day of your presentation, your group will lead the class discussion for the first 20-30 minutes of class. Your presentation should not simply be a reporting out of what you saw; rather, it should have a claim that is supported by primary research as well as theories regarding space via the readings we have done so far in class.

\section{What should we document?}

Here are some suggestions to get you started:

- The physical "ingredients" that are used to construct the POPS

- The objects (e.g., furniture, greenery, art) within the POPS

- The people interacting with the POPS

- The environment around the POPS

- Does your POPS differ from the environment around it? Does it fit in? Remember, the surrounding environment can help you learn more about the POPS itself.

- Your experience traveling to the POPS

- Could you get there by public transportation or is it accessible only by personal vehicles?

- Did you have a hard time finding it? How come?

\section{How should we document the POPS?}

Any or all of the following methods are encouraged:

- Photographs

- Moving images (video)

- Drawing or a diagram

- Audio recording of sounds

- Textual description

Basically, anything that will help you effectively bring your POPS into the classroom. You are not required to create a PowerPoint, but that may be the best medium for you to present some of the details you document. 


\section{What exactly should we be analyzing?}

The following set of guiding questions is repurposed from a textbook by Karla Saari Kitalong and Marcia Muth called Getting the Picture: A Brief Guide to Understanding and Creating Visual Texts. Like a critical reading of a written text, a close reading of a physical space involves careful, in-depth examination of the details that make up the space. Your reading should focus on the following three levels of questions:

\section{- Level 1: What is the big picture?}

- What is the situation or motivation for the construction of the POPS?

- What is its purpose?

- What audience(s) does the POPS seem to be meant for? Conversely, are there any audience(s) that are excluded?

\section{- Level 2: What characteristics of the space can you observe?}

- What objects are included in/around the POPS? How are they arranged? Cluttered? Sparse?

- What are the characteristics of the figures (i.e., people) in/around the POPS?

- What action(s) does the POPS seem to promote? What does it seem to shut down?

- What is the environment surrounding the POPS like? What features does it share with the POPS? What features are different?

- What elements contribute to the design of the POPS? What colors, shapes, or signs does it include? How are they arranged? Does the design of the POPS explicitly evoke any specific feeling, memory, or association?

- What can you hear as you are exploring the POPS? Is it loud? Quiet? What does this tell you about the POPS?

\section{- Level 3: How can you interpret what the POPS suggests?}

- What feeling or mood does it create? How does it create this mood?

- What sociological, political, economic, or cultural attitudes are reflected in the POPS?

- Are there any symbolic meanings behind the color, shapes, and signs of the text? Think about this: are there any differences between what the design explicitly states and what is symbolized?

- What theme(s) can you identify within the POPS?

One question to constantly keep in mind as you and your group members are investigating the space is what is excluded? Rhetorical analysis is not always about seeing what is 
there and what it means, but also what is not there, and thus what message is being conveyed by the fact that someone or something is not represented.

\section{What else should we consider when we are doing this assignment?}

- Respect others around you. Remember that you are sharing this space with others. Be careful about your noise level and shoving cameras in strangers' faces.

- Be honest. You have nothing to hide and the spaces you are visiting are deemed "public" spaces. If anyone is curious about what you guys are doing, tell them about this class. You may even want to bring this prompt along so they have a better sense of the assignment.

- With that said, POPS does stand for "privately owned public open spaces." You may encounter security or staff members that argue that these spaces still belong to private groups and thus may question you about your motives. Again, be polite, honest, and explain the situation. Feel free to give them my contact information and tell them to contact me with any questions or concerns they may have.

- Important: if something does come up during your exploration, your group may want to reflect upon it afterwards and think about what that situation contributes to the overall rhetoric of the POPS.

\section{References}

Cresswell, T. (2004). Place: An introduction. Malden, MA: Blackwell Publishing.

Deans, T. (2000). Writing partnerships: Service-learning in composition. Urbana, IL: National Council of Teachers of English.

DeLuca, K. M., \& Peeples, J. (2002). From public sphere to public screen: Democracy, activism, and the "violence" of Seattle. Critical Studies in Media Communication, 19 (2), 125-151. http://doi.org/https://doi.org/10.1080/07393180216559

Drew, J. (2001). The politics of place: Student travelers and pedagogical maps. In C. Weisser \& S. Dobrin (Eds.), Ecocomposition: Theoretical and pedagogical approaches (pp. 57-68). Albany, NY: State University of New York Press.

Guerra, J. C. (2015). Language, culture, identity and citizenship in college classrooms and communities. New York, NY: Routledge.

Jack, J. (2009). Review: Space, place, and the public face of composition. College English, 72(2), 188-198.

Mauk, J. (2003). Location, location, location: The "real" (e)states of being, writing, and thinking in composition. College English, 65(4), 368-388. 
McGee, M. C. (1982). A materialist's conception of rhetoric. In R. McKerrow (Ed.), Explorations in rhetoric: Studies in honor of Douglas Ehninger (pp. 23-48). Glenview, IL: Scott, Foresman.

Muth, M. F., \& Kitalong, K. S. (2004). Getting the picture: A brief guide to understanding and creating visual texts. Boston, MA: Bedford/St. Martin's.

Oldenburg, R. (1999). The great good place: Cafes, coffee shops, bookstores, bars, hair salons, and other hangouts at the heart of a community. New York, NY: Marlowe \& Company.

Rai, C. (2016). Democracy's lot: Rhetoric, publics, and the places of invention. Tuscaloosa, AL: University of Alabama Press.

Reynolds, N. (2007). Geographies of writing: Inhabiting places and encountering difference. Carbondale, IL: Southern Illinois University Press.

Schmidt, S. J. (2008). The evolving relationship between open space preservation and local planning practice. Journal of Planning History, 7(2), 91-112. http://doi.org/https: //doi.org/10.1177/1538513207304714

Tuan, Y.-F. (1977). Space and place: The perspective of experience. Minneapolis, MN: University of Minnesota Press.

van Huygen, M. (2018, January 29). Downtown Seattle is full of private-public spaces. Retrieved from https://seattle.curbed.com/maps/downtown-seattle-private-public-spaces

Wells, S. (1996). Rogue cops and health care: What do we want from public writing? College Composition and Communication, 47(3), 325-341. 